\title{
LÓGICA SIMBÓLICA, LÓGICA DIABÓLICA. LA RAZÓN FRONTERIZA COMO RESPUESTA A LA POSTMODERNIDAD
}

\author{
JONATAN CARO REY \\ Universidad de Deusto
}

\begin{abstract}
RESUMEN: El artículo se propone mostrar cómo la redefinición de la racionalidad en términos de «Razón fronteriza», realizada por Eugenio Trías, cobra su sentido más profundo al entenderla como propuesta alternativa a las derivas postmodernas de la racionalidad. Aunque la hipótesis puede ser extendida a su uso práctico, nos centramos exclusivamente en el uso teórico de la razón fronteriza. Para ello atendemos a las obras más maduras de la filosofía del límite, realizando un análisis intertextual mediante el que es posible entender algunos pasajes que, leídos de manera aislada, pueden parecer ambiguos o incomprensibles. Este análisis nos permite concluir que la apertura esencial de la «razón fronteriza» hacia el "suplemento simbólico» (también en su vertiente artística, pero sobre todo en su vertiente religiosa) revela su coherencia y su fuerza hermenéutica más genuina si se la interpreta a la luz de la polémica que la filosofía del límite mantiene con la postmodernidad.
\end{abstract}

PALABRAS CLAVE: razón fronteriza; postmodernidad; límite; disyunción; simbolismo; religión.

\section{Symbolic logic, diabolical logic. The border reason as a response to postmodernity}

ABSTRACT: The purpose of this article is to show how the redefinition that Eugenio Trias has made of rationality in terms of «border reason» (razónfronteriza) has a deeper meaning if understood as an alternative to the postmodern drifts of rationality. In spite of the fact that this hypothesis can have a practical point of view, this paper is only pointing out the theoretical aspect of border reason. For this reason, an intertextual analysis has been made of the mature works of the philosophy of the limit, and this allows to understand some passages that, if read in isolation, can be ambiguous or incomprehensible. The conclusion of this study shows that an opening towards a "symbolic supplement» (in its artistic, but above all in its religious aspect) reveals its coherence and its most genuine hermeneutics if it is interpreted in the light of the controversy that the philosophy of the limit has with postmodernism.

KEY WORDS: border reason; post modernity; limit; disjunction; symbolism; religion.

\section{INTRODUCCIÓN}

En 1985 la escritura de Eugenio Trías cambia drásticamente. La sensual atmósfera temática y estilística que envolvía las obras hasta entonces publicadas (magia, carnaval, deseo, pasión,...) dejaba paso a una austeridad conceptual que caracterizaría lo que él mismo consideraría como su propuesta de madurez, la más genuinamente filosófica: la filosofía del límite. Desde Los límites del mundo hasta sus últimas obras dedicadas a la música y el cine, todo su pensamiento girará en torno a un único concepto. O quizá mejor dicho en torno a un concepto único: el límite.

El propio autor confesaba en la obra que inauguraba esta propuesta lo que en cualquier caso era evidente. La idea del límite no era fruto de su originalidad. Pero sí lo eran tanto la reivindicación de su centralidad como el tratamiento filosófico que recibía en relación a la «modernidad». 
Era original la reivindicación, pues el límite no se presentaba tan sólo como un concepto reflexionado desde ese irrebasable marco histórico moderno. Más bien se tomaba la dirección inversa: era la propia modernidad en cuanto tal lo que se reflexionaba desde el concepto del límite. Y original era también, en efecto, el tratamiento, pues frente a la lectura unilateralmente negativa de la limitación, la cual gobernaría según Trías el pensamiento moderno, su filosofía abría una vía de interpretación del límite que sugería una modernidad alternativa (el tiempo dirá si también la in-auguraba); una forma diferente, suficientemente satisfactoria, de ser «moderno».

La propuesta se fue trabajando con atención y cuidado, dando lugar a un inmenso itinerario arquitectónico que, desde las claves conceptuales abiertas en Los límites del mundo (y también en La aventura filosófica), se extendería por las diferentes dimensiones del pensamiento filosófico. En la primera obra de balance (Ciudad sobre ciudad) se da cuenta de este recorrido a través de la metáfora de una "ciudadela del límite» compuesta por cuatro barrios: el estético, el religioso, el ético-político y el propiamente filosófico, presidido por el concepto que centrará nuestra atención en el presente artículo: la razón fronteriza.

En efecto, la figura de la «razón fronteriza» no agota la riqueza de la filosofía del límite. Pero sí la legitima filosóficamente en la medida en que, como propuesta conscientemente moderna, opta por someterse a la prueba de su «acreditación» racional. Trías lo expresa con claridad en la proposición XIX de La razón fronteriza:

«Este libro es, dentro de mi propia obra, una verdadera "piedra angular" sobre la cual ésta debe sustentarse. En él someto a mi filosofía del límite a su prueba decisiva, la prueba propiamente crítica, la que puede darle verdadera "carta de ciudadanía" filosófica. En él pongo a prueba, en el sentido kantiano del término "crítica", a un nuevo concepto de razón correspondiente a mi propia filosofía: lo que a lo largo del libro voy llamando razón fronteriza, o razón referida al concepto ontológico del ser del límite» .

Así pues, si somos capaces de entender las exigencias filosóficas que dan sentido a la figura conceptual de la «razón fronteriza», habremos reconocido el núcleo hermenéutico desde el que comprender el conjunto de la filosofía del límite, la cual no puede efectivamente reducirse, insistimos, a su dimensión gnoseológica.

\section{EL USO TEÓRICO DE LA RAZÓN FRONTERIZA: LA ESENCIA DEL LÍMITE Y LA VERDAD SIMBÓLICA}

El libro homónimo en el que se articula por vez primera esta figura se reconoce, ante todo, como una «teoría del conocimiento». Sin exclusividad, pues ya en la tercera parte de la obra se apunta a un uso práctico de la razón fronteriza que, de hecho, será desarrollado con total autoconciencia en obras sucesivas, sobre todo en Ética y condición humana y La política y su sombra. Pero es ciertamente en el uso teórico donde la razón fronteriza se reconoce de manera genética.

1 TRÍAs, E. La razón fronteriza, Destino, Barcelona, 1999, p. 423. 
Esto queda claro si atendemos al lugar que esta figura de la filosofía del límite ocupa en la tabla categorial, ars magna del pensamiento triasiano de madurez. Sin entrar en pormenores que no vienen al caso, baste con reparar en que la razón fronteriza, como quinta categoría de la tabla, aparece justo después del logos, según un recorrido fenomenológico que podemos resumir de la siguiente manera: la existencia ${ }^{2}$ como dato del comienzo, se ve impelida desde sí misma a la búsqueda de su propio origen (no el biológico o personal, sino el absoluto, el «origen de toda existencia»), experimentando así su remisión a la matriz ${ }^{3}$ de la cual procede. Pero lo que el sujeto experimenta es su remisión a la matriz, no la matriz misma, la cual permanece inaccesible al propio sujeto, revelando así el límite (tercera categoría) que le separa de la misma.

El logos (cuarta categoría) surge como interrogante ante esta condición en la que el sujeto se experimenta remitido a una matriz que le resulta inaccesible, debido al límite que de ella le separa. El sujeto se pregunta desde su experiencia limítrofe por la matriz, sin poder dar ninguna respuesta definitiva o plenamente satisfactoria al respecto. Y es en este contexto interrogativo y reflexivo donde hace su aparición la razón fronteriza como quinta categoría. Leemos en El hilo de la verdad:

«La quinta categoría es la categoría interpretativa y hermenéutica que surge de la auto-reflexión (crítica) que el logos, por su propio natural reflexivo, efectúa sobre sus propias formas y contenidos. De ahí brota, de la quinta categoría, la posibilidad misma de la filosofía. Y el concepto esclarecido de ésta como razón fronteriza. Se produce, pues, una remisión hermenéutica a las claves que permiten dar al logos refrendo crítico al esclarecerle su referencia al límite que le inviste» ${ }^{4}$.

Es por tanto legítimo centrar nuestra atención exclusiva en el uso teórico de la razón fronteriza, toda vez que esta categoría llega a reconocerse por primera vez en el mismo, al menos por lo que respecta a su génesis dentro de la filosofía del límite. Y lo que este uso teórico busca es, en coherencia con el recorrido fenomenológico indicado, la comprensión del límite, no como límite «de» o límite «entre»; no como límite que haya que superar para liberar aquello «de lo cual» es límite o para tender unilateralmente hacia uno de los polos «entre» los que ejerce la limitación. Se trata muy al contrario de pensar el límite en sí mismo (per se y en cuanto tal), en pura autorreferencia. O lo que es lo mismo, se trata de pensar la esencia del ser límite.

\subsection{Metodología propia de la razón fronteriza}

Pues bien, dicha esencia está constituida, según Trías, por dos potencias fundamentales: la disyuntiva y la conjuntiva. Pues, en efecto, todo límite, cualquier límite, es la vez punto o fuerza de unión y separación, de conjunción

2 Primera categoría en sentido fenomenológico y segunda en sentido ontológico.

3 Segunda categoría en sentido fenomenológico y primera en sentido ontológico.

4 Trías, E. El hilo de la verdad, Destino, Barcelona, 2004, p. 72. 
y disyunción. Que el autor las denomine «potencias» no es baladí: el límite puede separar o puede unir. En terminología aristotélica (en absoluto ajena al propio texto triasiano) diríamos que el límite es disyunción y conjunción en potencia. Y dependerá de cuál de las dos potencias se actualice (en virtud de un ser en acto que enfatice una de ambas) llegará a ser un límite que separa o une en acto, en la realidad efectiva.

Pero el límite en sí, esencialmente considerado, no es sólo disyunción, ni sólo conjunción. Tampoco es a veces una cosa y otras veces lo contrario, como si lo propio del límite fuera en ocasiones unir y en ocasiones separar. Esto queda claro cuando atendemos a la concepción triasiana de la «verdad», la cual caracterizará la metodología propia de la razón fronteriza en su uso teórico:

«La verdad señala el posible ajuste entre concepto y realidad. Establece la correlación que permite consumar, a través de ese ajuste, el conocimiento verdadero... tal verdad se concibió tradicionalmente como adecuatio, adecuación. Sólo que en la tradición no estaba especificada la tensión interna entre potencias en la que esa "adecuación" se juega. La concepción limítrofe de la verdad renueva, o recrea, esa idea de philosophiaperennis, sólo que mediante una decidida revisión de los términos de esa "conjunción". La verdad que aquí se propone como criterio asume la tensa relación entre ajuste y desajuste que la doble potencia esencial determina, y que debe hallarse tanto en el concepto como en la cosa, como desde luego en la co - relación de ambas que la verdad sanciona. La no - verdad podría determinarse como el ocultamiento u olvido de esa doble potencia en relación (bien en el concepto, bien en la cosa, bien en la co - relación entre los dos)» $»^{5}$.

Trías asume la definición clásica de la verdad en términos de adecuatio rei et intellectus. Sólo que tal adecuación entre el pensamiento y la realidad resulta más compleja que la presupuesta por el esquema tradicional, por cuanto que la esencia del límite, constituida por la doble potencia conjuntiva y disyuntiva, no permite simplificaciones en la «descripción» lógica de lo real. En toda facticidad opera la doble potencia del límite, siendo lo propio del uso teórico de la razón fronteriza remitir toda entidad concreta a esa esencia limítrofe dual (que no dualista), denunciando cualquier unilateralidad si la hubiere. La metodología de la razón fronteriza consistiría por tanto en mostrar cuál de las dos potencias del límite aparece enfatizada en cada existencia particular, para revelar acto seguido la presencia esencial de la otra potencia, aquella que permanecería en un segundo plano. La guerra y el amor reflejan para Trías esta dialéctica de forma ejemplar: en la primera predomina la potencia disyuntiva y en la segunda la conjuntiva. Pero la razón fronteriza sabe (y debe) descubrir el componente conjuntivo de juego (estrategia, competición,...) que hay en toda guerra y el componente de conflicto y lucha que hay en toda relación amorosa (así por ejemplo en los juegos de cortejo o en la sexualidad).

La verdad que busca la razón fronteriza no consiste, por tanto, en la adecuación entre la existencia y el concepto, sino entre éste y la realidad,

5 TRías, E. La razón fronteriza, Destino, Barcelona, 1999, pp. 238-239. 
entendida ésta como la remisión de esa misma existencia (quizá unilateral o demasiado enfáticamente instalada en la conjunción o en la disyunción) a la esencia limítrofe caracterizada por la doble potencia. Esto significa que, si bien no es legítimo en absoluto definir lo real en relación exclusiva a una de las dos potencias del límite, sí podría ser estratégicamente deseable en el proceder de la razón fronteriza (e incluso normativo), subrayar una de las dos potencias en aquellos casos en los que se aprecie una omnipresencia exclusiva o monopolizante de la otra.

\subsection{Simbolismo y razón fronteriza}

Pues bien, esta concepción de la verdad ayuda a entender el papel que juega la sexta categoría, el simbolismo, en la constitución de la razón fronteriza. Y es que la expresión que Trías elige para referirse a dicha categoría (suplemento simbólico), junto con el hecho de que la separe de la categoría referida a la propia razón fronteriza, puede llevarnos a pensar que el simbolismo es algo accesorio y secundario con respecto a la verdadera apuesta central de la gnoseología triasiana. Muy al contrario, buenos intérpretes como Patxi Lanceros han sabido reivindicar la consustancialidad del simbolismo en relación a la razón fronteriza:

"No haría yo, por ello, especial énfasis en el carácter "suplementario" del simbolismo. El símbolo es la razón fronteriza haciendo uso de "otro estilo", de otro conjunto de figuras retóricas (metonímia, prosopopeya, analogía,...). Por decirlo de otro modo, el símbolo es expresión de una razón poética (poiética) que inquieta y moviliza a una razón (la misma) que desde hace ya mucho tiempo se ha acostumbrado a su versión prosaica. La inquietud que el uso simbólico del lenguaje produce no entraña, sin embargo, ningún despropósito. Dinamiza el propósito de la razón: dar sentido, interpretar el mundo» ${ }^{6}$.

No es que la razón, experimentando los límites del logos como cuarta categoría, renuncie a sí misma en pro de algo distinto (el simbolismo). Como si dijéramos que, muy a su pesar, la razón tiene que delegar en el simbolismo lo que ella, en cuanto tal razón, no puede lograr por sí misma. De hecho la razón fronteriza, como quinta categoría, surge cuando ese logos que ha encontrado el límite negativo que separa su existencia de la matriz de la cual procede, descubre en la limitación no sólo la potencia disyuntiva, sino la posibilidad de una conjunción, si bien asintótica e imperfecta, en cuanto reconoce que el límite es también espacio de comunicación con ese Misterio matricial. Desde aquí la razón despliega su potencialidad en cuanto tal razón. Es la misma razón fronteriza, sólo que enfatizando la potencia conjuntiva de su logos a través de las formas simbólicas. Así pues, más que de «suplemento simbólico», tendríamos

6 Lanceros, P. «Desde la fundación de la ciudad. Exploración en la Ciudad Fronteriza», en Muñoz F. J. y Cabrero J. M. (eds.), La filosofía del límite. Debate con Eugenio Trías, Biblioteca Nueva, Madrid, 2005, p. 104. 
que pensar en la razón fronteriza como en un logos que de por sí es de naturaleza simbólica, en un sentido que el propio Trías explicita en su Lógica del límite:

«El título del libro no debería desorientar... se piensa en un logos (pensardecir) que tiene en el límite su raíz y su fundamento (ontológico), al cual se intenta, en el marco del libro, justificar. Significa, asimismo, que el límite, desde sí, puede revelar su propia "lógica" (Y a esa revelación se consagra este libro)... Se trata de hallar un modo de logos que es conforme o ajustado al limes. Tal modo es el que, a lo largo del libro, se define como logos figurativosimbólico»?

Mientras que el sujeto limitado desarrollaría el logos como cuarta categoría (logos que reconoce en el límite un non plus ultra de sus propias pretensiones), el sujeto fronterizo desarrollaría la razón fronteriza (quinta categoría), la cual, junto con el reconocimiento de la defección de sus pretensiones colonizadoras del cerco hermético (matriz misteriosa), reconocería también la posibilidad de comunicarse con dicho ámbito. De aquí que la razón fronteriza trascienda sus tradicionales conceptos (analíticos, clasificatorios) en los que opera la potencia disyuntiva (sin abandonarlos no obstante) para incorporar formas lógicas de naturaleza simbólica que, respetando la naturaleza hermética del cerco de lo encerrado en sí, puedan sin embargo atreverse a hablar del mismo y a referirlo, desde su potencia conjuntiva (evocadora, sugerente, metonímica, alegórica,...), integrando ambas dimensiones lógicas, la analítica y la simbólica, en un mismo discurso racional.

Decimos «respetando la naturaleza del misterio», pues el simbolismo no supone que la razón fronteriza, a través de sus formas lógico-simbólicas, pueda acceder a la matriz y agotar en términos de conocimiento el cerco hermético. En este sentido es absolutamente crucial no olvidar que el propio Trías ha distinguido tajantemente su propuesta simbólica de otras corrientes y escuelas, como la hermenéutica simbólica de inspiración jungiana, que según él defenderían una visión demasiado "vicaria» del simbolismo. Para estas corrientes los diferentes símbolos encontrarían su significado y sentido en ciertas claves reconocibles e identificables de nuestro imaginario sociocultural implícito (inconsciente colectivo), de tal forma que el trabajo hermenéutico consistiría en interpretar los fenómenos a la luz de los símbolos arquetípicos (inconscientes o subconscientes), en los que aquellos encontrarían su verdadera narrativa, su sentido cultural profundo. Muy al contrario el símbolo no puede reducirse, para Trías, a ninguna especie de lenguaje denotativo, por sofisticado que éste se presente. Y ello se debe, precisamente, a su intrínseca conexión con el cerco hermético, con el ámbito del misterio. Leemos en Lógica del límite:

«Por símbolo se entiende aquí un signo en el cual queda expresada la radical disimetría y no conmensurabilidad entre el significante y lo que con él

7 Trías, E. Lógica del límite, Destino, Barcelona, 1991, p. 31. Sentido que es coherente con el hecho de que en La edad del espíritu se proponga como horizonte o como proyecto un logos (lo que en dicho libro se denomina espíritu) que es síntesis de razón y simbolismo. 
se pretende significar. El referente del símbolo es, pues, inconmensurable (se cierra en el cerco hermético). De ese referente tan sólo subiste un resto, cuya relación con el referente es indirecta. El símbolo jamás denota; únicamente connota. No designa sino que alude. Borra, pues, la denotación y la designación (de carácter apofántico) destacando únicamente a través de una forma sensible (o de un dispositivo complejo de carácter formal-sensible), conexiones o asociaciones indirectas, libres, laxas, a través de las cuales cierto referente, de carácter enigmático (inconcebible) es aludido» ${ }^{8}$.

El símbolo «algo» nos dice (y nos da a conocer) del ámbito del misterio, al contrario que el concepto, incapaz de darnos noticia alguna de esa dimensión hermética de nuestra realidad, en la medida en que dicha dimensión es (como nos dice Trías sin inocencia alguna) «inconcebible», esto es, inapresable según los términos del conocimiento referencial (conceptual) con el que «apresamos» analíticamente el acontecer del cerco del aparecer. Lo que el símbolo nos revela del cerco hermético es un «resto», una alusión indirecta al mismo, la cual no nos permite conocer nada concreto del mundo del enigma, precisamente porque es una forma lógica respetuosa con aquel ámbito al que se haya referida. Ahora bien, ¿cómo entender entonces la siguiente intervención de Trías en torno al necesario convencionalismo que, como nuestro filósofo reconoce, acompaña siempre al simbolismo?

«Sin convención no hay espacio de simbolización. La cópula que une el objeto sensible (símbolo) y lo que ese objeto simboliza (referente de significación), debe constituir cierta convención... Lo importante de esas convenciones consiste en su capacidad de despertar ciertas emociones, o de provocarlas y suscitarlas. Cierto que ese despertar sólo es posible en tanto se mantenga el consenso en relación con la vigencia de esas convenciones. Como tales, son convenciones precisamente porque se espera de ellas que provoquen tales o cuales emociones ${ }^{9}$.

En nuestra opinión cuando Trías nos habla del símbolo, como de aquella forma lógica con la que nos es dado conocer el cerco hermético, no quiere decir que nos proporcione un conocimiento de dicho cerco similar al que el conocimiento conceptual nos proporciona con respecto al cerco del aparecer. El símbolo, según Trías, jamás denota, sino que connota: su papel no es producir un conocimiento evidente (claro y distinto) como el conocimiento conceptual, sino extraer las connotaciones de dicho conocimiento (ocultas u eclipsadas por su carácter denotativo), a fin de abrirlas a la realidad hermética que también constituye, como dimensión ineludible de la realidad y de la experiencia del sujeto, un ámbito determinante del saber.

Y precisamente por esto, en medio del lenguaje conceptual, el símbolo necesita ser convencional: asumiendo la convencionalidad del pensar-decir denotativo, el símbolo es capaz de abrir la denotación de dicho convencionalismo

$8 \quad$ Ibid. P. 60.

$9 \quad$ Ibíd. pp. 67-68. 
lingüístico-conceptual más allá de sus barreras, mediante la promoción de la dimensión connotativa del logos, la cual sólo es posibilitada por el espacio abierto que supone la incorporación al discurso de la dimensión hermética. Algo propiciado, precisamente, por la comparecencia de las formas lógicosimbólicas en el cerco del aparecer. El símbolo ensancha nuestro conocimiento conceptual (referido al cerco del aparecer), obligándolo a relativizar sus pretensiones denotativas o apofánticas mediante la constatación, more symbolico, de intuiciones e insinuaciones implícitas en medio de las definiciones pretendidamente «precisas» del pensar-decir conceptual. Lo cual logra el logos simbólico mediante el despliegue de metonimias, analogías y otros recursos que hacen que aquello que trasciende el lenguaje denotativo esté presente en el discurso como forma positiva de conocimiento ${ }^{10}$.

Todo el intento se cifra, por tanto, en que la razón fronteriza conozca el cerco del aparecer no de forma unilateral (desde sus propios parámetros), sino en consonancia con la constatación del irrenunciable cerco hermético. De aquí que Trías afirme, en el tercer movimiento de la Lógica del límite, que el concepto correspondiente a la inspiración limítrofe de su propuesta «es un concepto exstático, abierto a lo simbólico, que jamás se enrosca en su propia transparencia racional» ${ }^{11}$.

\section{LA RAZÓN FRONTERIZA Y SU SOMBRA: EL SIMBOLISMO ANTE EL RETO POSTMODERNO}

Llegados a este punto es preciso recordar el contexto polémico en el que nace la filosofía del límite. Son múltiples las incursiones en las que Trías identifica claramente al enemigo íntimo frente al cual se gesta y se forma su pensamiento de madurez. Baste con recordar el siguiente balance de su trayectoria:

"Cuando inicié mi itinerario de pensamiento, la filosofía parecía despeñarse ante la embestida de dos monstruos. Se hallaba asediada por la Scilla de una Razón analítica de orientación positivista... Si quería subsistir inmune a ese envite, corría el riesgo de perecer en la Caribdis de una Razón dialéctica, de orientación materialista, que concebía la filosofía como el broche ideológico de las superestructuras del poder socioeconómico... Hoy son otras las dificultades que asedian y asaltan a la razón filosófica....Hoy se corre el riesgo "posmoderno" de diluir la especificidad de la filosofía en una indeterminada

10 Estas apreciaciones son coherentes con la definición que hace Trías de la filosofía como literatura de conocimiento: se trataría de proponer un pensamiento alternativo a la pura narratividad postmoderna o al conceptualismo idealista, por cuanto supone un híbrido entre el pensamiento y el lenguaje conceptual denotativo y el pensamiento y el lenguaje simbólico connotativo. La escritura se vuelve entonces literatura de conocimiento, capaz de conjugar momentos conceptuales y momentos simbólicos, e incluso de incluir simbología en el concepto y aclaraciones en los símbolos. De esta forma la razón fronteriza se sabe a sí misma dotada de ambos instrumentos, el conceptual y el simbólico, como sus recursos propios e intrínsecos a su propia naturaleza, sin necesidad de tener que elegir entre ellos.

$11 \quad$ Ibid. p. 418. 
textualidad, o en una extrapolada y mal comprendida razón narrativa en la cual se confunden, en feliz promiscuidad, toda suerte de formas de escritura y de relato, los literarios, los filosóficos, etc. En la noche de la narratividad, podría decirse, con Hegel, que todas las vacas parecen pardas ${ }^{12}$.

\subsection{Filosofía del límite y postmodernidad}

La sombra que como reto provoca el despliegue de la filosofía del límite es pues la postmodernidad, la cual no implica para Trías ruptura radical con respecto a una modernidad supuestamente superada o en vías de superación. En efecto, su visión se aleja de aquellas interpretaciones que tienden a considerar la postmodernidad como un tiempo nuevo. De hecho no demuestra ningún interés en dialogar con propuestas ciertamente interesantes como la teoría del simulacro de Baudrillard, la deconstrucción textual derridiana o la sociedad del consumo de Bauman.

Siguiendo la lógica abierta por autores como Vattimo, Trías considera que las derivas postmodernas de la cultura pueden ser entendidas, más bien, como el desarrollo de ciertas tendencias disolventes que la propia Modernidad llevaría en su seno desde el principio: al igual que el Progreso sustituyó a la idea de la Providencia, el Nihilismo habría sustituido la idea (y la fe) del Progreso como reflexivo derivado siniestro de la misma. En este sentido cabe recordar que, ya en la primera entrega de la filosofía del límite, Trías identificaba desde el comienzo la Modernidad como el marco histórico irrebasable desde el que el pensamiento filosófico debía alzarse. No vamos a insistir en esta apreciación que avalados intérpretes como José Manuel Martínez-Pulet han subrayado ya con sobrada solvencia. La postmodernidad que es preciso combatir es para Trías una modalidad de lo moderno que nace de los impulsos secularizadores y relativizadores latentes, desde el principio, en el seno de la propia Modernidad.

Sin embargo esta corrección debe hacerse sin caer en la pura regresión. Pues tan alejado está el tratamiento que Trías realiza de la postmodernidad de las posturas que subrayan su pretendida novedad frente a lo moderno, como de los reaccionarios que, o bien pretenden simplemente restaurar la modernidad anterior una vez constatado el fracaso postmoderno (como Ernest Gellner), o bien tratan de promover «más y mejor» modernidad, a fin de llevar a buen término un proyecto ilustrado que simplemente habría quedado incompleto (como reivindica Habermas). Fernando Pérez Borbujo sonsacó a Trías un balance claro de su posición en relación a este debate:

«A partir de Los límites del mundo inicio una aventura muy particular, una aventura ontológica, de filosofía primera; una filosofía que va a plantear los grandes temas de la filosofía en el nuevo mundo que estamos inaugurando. No es casual que coincida con el desencadenamiento de una gran polémica que ha determinado y marcado, en mi opinión, el mundo de la filosofía y la

12 TRíAs, E., Ciudad sobre ciudad, Destino, Barcelona, 2001, p. 22. 
cultura en general en estas dos últimas décadas, la polémica en torno a la modernidad y a la posmodernidad y en la que trato de encontrar un punto medio que no sea ni una entrega sin más, ni un posmodernismo irresponsable; ni tampoco una especie de resquemor envejecido y caduco» ${ }^{13}$.

Hechas estas precisiones podemos entender mejor la caracterización triasiana de la postmodernidad como una «época» en la que la potencia disyuntiva adquiere un protagonismo desmedido en relación a la cuestión de la «verdad»:

«Sobre todo en la fenecida década de los ochenta, la década posmoderna por antonomasia, esta cuestión de la verdad pareció definitivamente periclitada. Los principales conceptos ontológicos de la philosophiaperennis, "verdad", "fundamentación", "ser", etc., parecían derrumbarse de forma definitiva. Pensadores como Rorty o Vattimo y otros parecían sus definitivos enterradores... Hoy, ahora, pasado este aquelarre destructor, subsisten importantes piedras desechadas por esta general demolición. Y es importante recatarlas. O hacer de ellas, como dice el evangelio, la posible "piedra angular" de una nueva edificación. Se trata de asumir, y superar a un tiempo, según un modo diferente del hegeliano de comprender la Aufhebung, esa vertiginosa, y saludable, tarea de des - construcción, integrando de ella lo que constituye su potencia: eso que llamo potencia disyuntiva. Pero se trata (por lo que a mi propia propuesta filosófica se refiere) de comprender la relación (conflictiva, trágica) de esa instancia de disyunción con la otra potencia con la cual se halla intrínsecamente hermanada, la potencia conjuntiva» ${ }^{14}$.

Como dijimos, la razón fronteriza reflexiona la esencia del ser del límite en la doble potencia conjuntiva y disyuntiva. Desde aquí su metodología consiste en remitir la existencia a la esencia mostrando, en caso de unilateralidades, que ambas potencias están siempre presentes, para lo cual es estratégicamente legítimo enfatizar la potencia coyunturalmente solapada o eclipsada en cada caso. Por otro lado el fragmento reproducido afirma que la postmodernidad se caracteriza como una época en la que la cuestión de la verdad, aquella en torno a la cual se constituye toda gnoseología, se halla periclitada. Y parece que ello se debe, fundamentalmente, al énfasis unilateral y desmedido de la potencia disyuntiva. Como si dijésemos que el concepto de verdad se hubiera disuelto a base de multiplicar el reconocimiento de las diferencias y matices que separan y distinguen la(s) realidad(es), dando paso a una forma de racionalidad o lógica sin criterio firme, basada en la pura narratividad de los casos singulares.

Teniendo en cuenta ambos apuntes, ¿cabe pensar en la importancia que Trías atribuye al simbolismo, como el subrayado estratégico que la razón fronteriza realizaría de la potencia conjuntiva en respuesta al exceso disyuntivo (dia-bólico en sentido etimológico) de la postmodernidad? Podemos sustentar esta interpretación reparando en esa gran obra de filosofía de la religión, pero

13 Pérez-Borbujo, F. «Ensayo y sistema. Entrevista a Eugenio Trías», en Sánchez, A. y Rodriguez Tous, J. A. (eds.) Eugenio Trías: El límite, el símbolo y las sombras, Destino, Barcelona, 2003, p. 36.

14 TRías, E. La razón fronteriza, Destino, Barcelona, 1999, pp. 224-225 
también de filosofía de la historia, que es La edad del espíritu. Y es que lo que en este texto comienza como una búsqueda de las condiciones fenomenológicas del acontecimiento simbólico, termina ofreciendo un esquema conceptual para la comprensión de nuestra historia, cuyo balance de la Modernidad ha quedado bien resumido en estas palabras de Francisco José Martín:

«La Modernidad es, ahora, "el tiempo de la gran ocultación". Se trata, a decir de Trías, de la Gran Ocultación de lo sagrado y de lo simbólico. La Modernidades el ámbito de la "revelación de la razón", el ámbito en que lo simbólico queda progresivamente "inhibido"... la Filosofía del Límite pro-pone como horizonte para habitar una modernidad-en-crisis... la búsqueda de una razón capaz de revelarse sin dañar ("inhibir", "ocultar") el potencial simbólico en que adviene. Una razón del límite, o como Trías la llama, fronteriza» ${ }^{15}$.

La filosofía de la historia que propone La edad del espíritu presenta el acontecer de la misma en tres edades, siendo la última una época postulada como horizonte deseable, alternativo a la propia historia contemporánea reflexionada como segunda edad. Historia contemporánea que La razón fronteriza y obras posteriores identificarán directamente con la postmodernidad como «edad del nihilismo», descrita precisamente en términos dia-bólicos, disyuntivos:

«Tal nihilismo acucia y asedia la experiencia contemporánea que vive el tránsito entre el sexto y el séptimo eón. Constituye su más peculiar cesura diabálica, así como la más temible prueba del espíritu. Nietzsche (y Heidegger también) localizaron ese "huésped inhóspito" que provoca la pérdida de "todo horizonte". La tierra se desengancha de su sol. El polo que permite al ethos orientarse desaparece del campo visual. Ya no hay luz que haga posible distinguir entre bienes, valores, estimaciones. No hay, por tanto, criterios ni paradigmas de conocimiento, de conducta y sentimiento. No hay términos que confieran finalismo a la facultad de desear. La filosofía del límite, que confiere a esa línea del horizonte prerrogativas ontológicas, constituye, en relación al nihilismo, una alternativa a esta gran prueba espiritual» ${ }^{16}$.

\subsection{Logos diabólico y simbolismo}

Frente a ese logos dia-bólico, característico de una postmodernidad instalada en la potencia disyuntiva, la razón fronteriza reivindicaría el simbolismo consustancial a su propia naturaleza, presentándose a sí misma como una lógica sim-bólica capaz de contrarrestar la unilateralidad postmoderna mediante el subrayado estratégico de la potencia conjuntiva.

Pues bien, como es sabido tanto el ámbito religioso como el artístico sirven a la razón fronteriza en este ejercicio: ambos son mundos simbólicos que permiten abrir el pensar-decir conceptual, denotativo o apofántico, a las

15 Martín, F. J. (2005). «Modernidad y límite. Apuntes para una contextualización intelectual», en MuÑoz F. J. y CABRERo J. M. (eds.), La filosofía del límite. Debate con Eugenio Trías, Biblioteca Nueva, Madrid, 2005, p. 32.

16 Trías, E. La edad del espíritu, Destino, Barcelona, 1994, pp. 671-672. 
connotaciones que se despliegan desde la conexión y la comunicación que las formas simbólicas favorecen con el cerco hermético. Sin embargo, en un pasaje fugaz pero significativo de Ciudad sobre ciudad, Trías sugiere un protagonismo diferente para cada una de estas esferas del simbolismo, según nos atengamos al uso teórico o al uso práctico de la razón fronteriza:

«Entre la razón fronteriza en su uso gnoseológico, o estrictamente filosófico, y el simbolismo en su uso religioso, se advirtió ya ese parentesco ... Lo mismo puede y debe decirse en relación al nexo (diferenciante y unitivo) que puede advertirse en el barrio sur de la ciudad fronteriza, entre el barrio relativo al uso práctico, o ético, de la razón fronteriza, y al uso poiético, o estético-artístico, del suplemento simbólico. Se trata de mostrar, como es de rigor, las obvias conexiones entre la ética y la estética, o entre la praxis y la poiesis» ${ }^{17}$.

Nada se nos dice en el texto reproducido acerca del papel gnoseológico del simbolismo artístico o estético. Lo cual no implica que la estética y el arte no aporten nada a la esfera del conocimiento propio del sujeto fronterizo. Sin embargo, siguiendo el fragmento reproducido, el simbolismo religioso parece guardar una familiaridad especial con la dimensión cognoscitiva de la razón fronteriza.

Aunque Trías no ofrece ninguna razón explícita de estas familiaridades, podemos sugerir, con base en sus textos, dos posibles motivos que avalarían una mayor intimidad entre el simbolismo religioso y el uso teórico de la razón fronteriza. El primer motivo giraría en torno a los fundamentos de la racionalidad fronteriza, mientras que el segundo lo haría en torno a la cuestión de su finalidad.

Por lo que respecta al fundamento de la razón fronteriza, el concepto de «revelación» juega un papel crucial. Distanciándose de toda inspiración idealista Trías afirma que la razón es incapaz de autoengendrarse. La puesta en marcha y el desarrollo del ejercicio racional exigen siempre un dato previo que no puede ser deducido por la propia razón desde sí misma. Depende, por el contrario, de un positum: algo puesto o impuesto a la razón; algo con lo que la razón se encuentra; algo que la razón no decide para sí, sino que «le viene dado». Tal positividad es la existencia. En efecto, en el contexto de La razón fronteriza el conocimiento surge (primero como interrogante, después como intento de respuesta) ante la constatación del factum de la existencia. Arash Arjomandi ha sistematizado los dos sentidos en que, partiendo de esta constatación, se puede hablar de la fundamentación de la razón fronteriza en términos de «revelación»:

1) Habría un sentido apriórico, el cual se plantearía en los términos ontológicos ya referidos en el apartado anterior: la remisión de la existencia a la matriz revela el misterio último con el que dicha existencia está conectada por y desde el límite. De aquí surge la razón fronteriza como interrogante acerca de esa existencia en exilio y éxodo con respecto a su fundamento en falta.

17 Trí́s, E. Ciudad sobre ciudad, Destino, Barcelona, 2001, pp. 246-247. 
2) Pero resulta que, además, en la búsqueda de esa respuesta la razón fronteriza se sirve, a posteriori, de un acervo lingüístico y conceptual que tampoco ha producido por sí misma, sino que la antecede.

Siguiendo la inspiración del trabajo de Arjomandi, propondríamos distinguir entre una revelación ontológica y una revelación hermenéutica en relación al fundamento de la razón fronteriza; revelaciones que la precederían tanto en su «nacimiento» como en su «despliegue». La razón surgiría a partir de la revelación ontológica de la existencia referida a la matriz, en cuanto dato previo ofrecido al logos a través de la mediación del límite. Y esta razón se desplegaría, en su intento por buscar sentido a la existencia desprendida de la matriz, a través de recursos que también le vendrían dados por mediación histórico-lingüística. En este punto Trías coincide con la crítica del postmodernismo a la forma ilustradaidealista de concebir la racionalidad, tal y como declara en Pensar la religión:

«Lo propio de la conciencia postmoderna consiste en la aceptación de que la razón no puede autofundarse sino que requiere, para su propia constitución, una trama lingüística y narrativa en la cual se halla entretejida... De hecho el postmodernismo restablece el primado lingüístico y narrativo como la materia que todo proyecto reflexivo, sapiencial o filosófico, presupone. Toda razón, a partir del postmodernismo, asume la condición, enunciada por vez primera por Schelling, de ser siempre supernumeraria en relación a una antecedente revelación ${ }^{18}$.

Pero, acto seguido, Trías da un paso más allá en esta operación arqueológica, distanciándose del postmodernismo y reivindicando un sustrato anterior a la propia textualidad y narratividad del pensamiento. Sustrato de raigambre religiosa:

«... en el subsuelo o en el fundamento de ese entretejido textual o narrativo se apercibe una raíz de naturaleza cultual que remite a un marco religioso: aquel que determina el orden de lenguaje y de cultura en el que el lenguaje y la cultura se afincan. Al final del episodio postmoderno sobreviene ese reconocimiento de las raíces religiosas que subyacen, a modo de revelaciones simbólicas inconscientes, los diferentes marcos culturales, con sus formas propias de leguaje, narración y escritura... Esto es lo que distancia mi posición respecto a ese episodio postmoderno. Yo parto de la premisa de que importa afirmar, frente al énfasis postmoderno en favor de la narración y la textualidad, una previa y presupuesta revelación religiosa, que es la que en todo caso confiere fundamento y validez al propio proyecto postmoderno» ${ }^{19}$.

Cuando la razón fronteriza descubre la revelación hermenéutica que la precede, comparte el momento del postmodernismo: el ejercicio racional depende del entretejido lingüístico y narrativo en el que siempre tiene lugar. Pero este momento, desde las coordenadas de la filosofía del límite, es negativo: esos usos impiden aproximarse a la matriz, encerrada como está espacialmente

18 TRÍAs, E. Pensar la religión, Destino, Barcelona, 1997, pp. 34-35.

19 Ibid., pp. 35-36. 
en el cerco hermético y temporalmente en el pasado inmemorial, en la medida en que son usos lingüísticos propios de un mundo tardomoderno que permanece instalado en el cerco del aparecer. Retrotrayendo dichos usos de escritura, narración y lenguaje a su marco de constitución religioso (determinante en sentido de precedencia histórica y cultural), la razón halla, sin embargo, un sustrato en el que se han desarrollado unas formas lógicas capaces de dar noticia de la matriz existencial (capaces, literalmente, de notificarla), constituyéndola así en presencia con la que comunicarse de manera positiva, si bien siempre imperfecta: las formas simbólicas.

Así pues el primer contacto con el simbolismo como algo precedente a la razón, se opera en la esfera religiosa, no en la artística ${ }^{20}$. Sin ir más lejos, la tabla de las categorías, propuesta como ars magna de la filosofía del límite, tiene su reconocido precedente en la reflexión realizada en La edad del espíritu sobre el acontecimiento simbólico-religioso. Es en efecto en el contexto del estudio de la religión donde aparecen por primera vez, en clave simbólica-diabólica, las siete categorías que más tarde, en La razón fronteriza, serán sometidas a una «destilación» estrictamente conceptual.

Pero hay, como indicábamos, un segundo motivo que explicaría la especial familiaridad entre la razón fronteriza en su uso teórico y el simbolismo religioso. Motivo que apuntaría a la finalidad que para Trías comparten la religión y la razón. Respecto de la primera afirma nuestro autor que, de entre todas las razones que explican (parcialmente) la necesidad de la religión, una sigue siendo la más básica e incontestable de todas: la presencia ineludible de la muerte en el horizonte de la existencia humana. Desde siempre la religión se sabe (incluso entre sus férreos detractores, como en Marx) suspiro, grito y llanto de la criatura oprimida. Toda opresión da pábulo (y aliento) a la religión como forma de consuelo y (en sus más lúcidas versiones) como forma de solidaridad activa para con los oprimidos. Pero, de entre todos los opresores posibles, la muerte destaca como aquel poder que nos oprime a todos y a todas sin excepción: al rico y al pobre; al más oprimido y al más opresor de los seres humanos.

Frente a este poder opresor por antonomasia la humanidad habría desplegado, desde sus orígenes, dos formas fundamentales de oposición: la magia y la religión. En la magia, que desde la prehistoria documenta sobre la búsqueda de vida más allá (y a pesar) de la muerte, el ser humano desplegó «tecnologías» (en sentido focucaultiano) a través de las cuales (ritos, conjuros,...) pretendía someter a la muerte, mediante el dominio de instancias sobrenaturales con poder de decisión (e intercesión) sobre ella. La religión, más atenta a la condición mortal y por ello más humilde, reconocía que frente a la muerte y su dimensión sobrenatural el ser humano no disponía, en último término, de poder alguno: no se podía doblegar la voluntad sobrenatural a la voluntad humana. «La religión», escribe Trías, «en lugar de querer dominar lo sacro, se

20 De hecho, como afirma el propio Trías, el arte tuvo que esperar siglos para independizarse de la raigambre religiosa. 
postra ante el misterio consternada». La religión sigue creyendo en el Poder de lo Sagrado (sobrenatural) sobre la muerte (y contra ella). Sólo que espera que el cambio de la aciaga suerte mortal venga motivado por la sumisión a lo sagrado en lugar de por su dominio. Del sometimiento a esa instancia sagrada con poder sobre la Muerte se espera la Salvación. Esperanza y Salvación son las claves que permiten comprender la esencia de la religión en la medida en que, según Trías, ésta nace como respuesta ante la terrible e inevitable opresión universal de la Muerte.

Pues bien, resulta que en este interesante librito se afirma que es la Muerte la que explica, también, el surgimiento de la inteligencia humana:

"¿Qué es lo que hace que ese habitante del mundo disponga, como uno de sus más preciados dones, de la capacidad de intelección y conocimiento en relación a sí mismo y a cuánto le rodea? Una capacidad únicamente confrontada a una constante propensión a contradecirla a cada paso a través de yerros, obcecaciones y obnubilaciones de esa su misma facultad tan primorosa. No pregunto por el origen biológico o evolutivo de ese tesoro humano (que puede ser, desde luego, un regalo envenenado). Pregunto por la razón de ser, en términos filosóficos, de esa facultad. Creo desde hace ya tiempo que en este punto la Muerte viene en nuestro auxilio. Me explicaré. Creo que la comprensión de nuestra condición mortal constituye el paradigma, el modelo o el patrón de toda posible comprensión (de nosotros mismos, de nuestros prójimos y lejanos y del mundo en general). Creo que somos inteligentes porque nos sabemos mortales. O que es la conciencia (primero oscura, luego más y mejor clarificada) de esa condición mortal lo que provoca en nosotros el salto a la condición inteligente que nos determina y define como humanos. O que salimos del entumecimiento vegetal y de la semiconsciencia animal en virtud de esa provocación que constituye la conciencia de la muerte. La muerte está ahí para asistirnos y provocarnos, como en el bello Lied de Schubert. Está ahí, con la mano tendida, como ante la joven doncella, despertándonos de nuestra pura condición de especie animal, y elevándonos (¿o rebajándonos, quizá?) a la condición humana. Y eso sucede porque la presencia de la muerte despierta nuestra conciencia, la convierte en conciencia inteligente, o en conciencia capaz de comprensión, de intelección ${ }^{21}$.

La inteligencia nace como intento de exorcizar el sinsentido de la existencia, al que se halla sometida por la opresión de la Muerte. La religión y la razón (y por ende la filosofía) comparten para Trías una misma finalidad que las hermana, por tanto, no sólo en el fundamento (según lo dicho) sino en todo su desarrollo. Razón y religión comparten la misión de dar sentido a la existencia, de interpretarla y ofrecer una comprensión de la misma capaz de hacer soportable lo que de por sí (y para todos) es insoportable: la conciencia de la muerte.

Por esto el religioso es la forma específica de simbolismo que corresponde al uso teórico de la razón fronteriza: no sólo porque la razón fronteriza encuentre sus categorías en el contexto del acontecimiento simbólico religioso. Si de hecho las encuentra ahí es porque en dicho simbolismo, más que en el artístico, se

${ }^{21} \quad$ Ibid., pp. 30-31. 
condensa el trabajo de siglos del lenguaje simbólico de la tradición religiosa, en su afán por comunicarse con lo sagrado (el cerco hermético) para dar sentido a una existencia mortal. La Muerte, como paradigma de todo límite negativo, debe ser positivamente integrada en la existencia (según la visión positiva de la limitación característica de la filosofía del límite). Y esto sólo puede hacerlo una Razón Fronteriza capaz de desplegar, junto con los conceptos habituales, las formas que el simbolismo religioso le ofrece como materia y cauce de su reflexión.

En conclusión, la razón fronteriza debe entenderse como respuesta alternativa a una racionalidad postmoderna que, debido a las múltiples defecciones experimentadas ante los diversos obstáculos que ha encontrado en su intento por comprender el mundo, ha terminado por ver en la limitación algo exclusivamente negativo, algo que impide la relación de la razón con aquello que no puede comprender. El postmodernismo enfatiza así de forma unilateral (prácticamente excluyente) la potencia negativa de la disyunción (diabólica en sentido etimológico) que Trías reconoce también como esencialmente constituyente de la limitación. Sólo que su filosofía reivindica la positividad también esencial del límite, negada por esa parcialidad postmoderna.

En términos gnoseológicos esto implica reivindicar la capacidad de la razón por relacionarse positivamente con lo que acontece más allá del límite con el que se topa el sujeto en su experiencia ubicada en el cerco del aparecer (el cerco hermético). Y es en este sentido como hay que entender la relación de ese (en nuestra opinión desacertadamente denominado) suplemento simbólico, de naturaleza no exclusiva pero sí fundamentalmente religioso en relación a su uso teórico.

La razón fronteriza supone la propuesta de una lógica simbólica, pensada como alternativa a la lógica diabólica que caracteriza un tiempo postmoderno de vida y pensamiento, el cual enfatiza unilateralmente la potencia disyuntiva de la razón, exaltando las diferencias hasta derivar en el contrasentido de anularlas en una pura narratividad en la que cada verdad, extremadamente aislada y diferenciada del resto, naufraga a la deriva, sin poder llegar a ofrecer una adecuada comprensión del mundo.

\section{BibLiografía}

Arjomandi, A. (2007). Razón y revelación. La religión en el proyecto filosófico de Eugenio Trías. Barcelona: El Cobre.

Lanceros, P. (2005).«Desde la fundación de la ciudad. Exploración en la Ciudad Fronteriza», en Muñoz F. J. y Cabrero J. M. (eds.), La filosofía del límite. Debate con Eugenio Trías. Madrid: Biblioteca Nueva, pp. 91-108.

Lyon, D. (2005). Postmodernidad. Madrid: Alianza.

Martín, F. J. (2005). «Modernidad y límite. Apuntes para una contextualización intelectual», en Muñoz F. J. y Cabrero J. M. (eds.), La filosofía del límite. Debate con Eugenio Trías. Madrid: Biblioteca Nueva, pp. 91-108. 
Martínez-Pulet, J. M. (2003). Variaciones del límite. La filosofía de Eugenio Trías. Madrid: Noesis.

Pérez-Borbujo, F. (2003). «Ensayo y sistema. Entrevista a Eugenio Trías», en Sánchez, A. y RodriguezTous, J. A. (eds.) Eugenio Trías:El límite, el símbolo y las sombras. Barcelona: Destino, pp. 13-58.

Trías, E. (1991). Lógica del límite. Barcelona: Destino.

- (1994). La edad del espíritu. Barcelona: Destino.

- (1997). Pensar la religión. Barcelona: Destino.

- (1999). La razón fronteriza. Barcelona: Destino.

- (2001). Ciudad sobre ciudad. Barcelona: Destino.

- (2004). El hilo de la verdad. Barcelona: Destino.

Universidad de Deusto

Jonatan CARo Rey

Avenida de las Universidades 24, 48007 Bilbao

jonatan.caro@deusto.es

[Artículo aprobado para publicación en enero de 2018] 